\title{
A LOWER BOUND ON THE NUMBER OF FINITE SIMPLE GROUPS
}

\author{
MICHAEL E. MAYS \\ Department of Mathematics \\ West Virginia University \\ Morgantown, West Virginia 26506 \\ U.S.A.
}

(Received March 5, 1980)

ABSTRACT. Let $S(n)=\mid\{m<n$ : there is a (non-cyclic) simple group of order $m\} \mid$. Investigation of known families of simple groups provides the lower bound $S(n) \gg n^{1 / 4} / \log n$.

KEY WORDS AND PHRASES. Simple group, asymptotic formula. 1980 MATHEMATICAL SUBJECT CLASSIFICATION. Primary 20006.

The non-specialist reader should refer first to Hurley and Rudvalis (4). Write $S(n)=\mid\{m<n$ : there is a simple group of order $m\} \mid$ and $S^{\prime}(n)=\mid\{G$ : $G$ is a simple group and $|G|<n\} \mid$. Dornhoff (1), Dornhoff and Spitznagel (2), and Erdös (3) got successively better upper bounds for $S(n)$ by refining an argument which uses the Sylow theorems to generate a necessary criterion for a simple group of order $m$ to exist. From the observation that $S(n) \leq \mid f m<n$ : for any prime $\mathrm{p} \mid \mathrm{m}$ there is a $\mathrm{d} \mid \mathrm{m}$ such that $\mathrm{d}>1$ and $\mathrm{d} \equiv 1(\bmod \mathrm{p})\} \mid$ Dornhoff found that 
$S(n)=o(n)$ and Erdös derived a complicated bound better than that of Dornhoff but not as good as $o\left(n^{1-\varepsilon}\right)$. It should be noted that in general $S(n)<S^{\prime}(n)$ because it occasionally (in fact infinftely often) happens that non-1somorphic simple groups of the same order exist.

We offer the following lower bound for $S(n)$, hence for $S^{\prime}(n)$

THEOREM. $S(n) \gg n^{1 / 4} / \log n$.

PROOF. We estimate the number of integers $m<n$ which can be the order of a simple group in one of the known families and note that in all but finitely many cases the orders of the groups in that family are distinct.

From a list of known families of simple groups (4, p. 708) we see that one family dominates in the sense that for $F_{1}(n)=\mid\{m<n$ : $m$ is the order of a simple group in family 1$\} \mid, F_{1}(n)=0\left(F_{1}(n)\right)$ for any $1 . F_{1}(n)$ is the number of simple projective special linear groups of order less than $n$.

Thus to estimate $S(n)$ from below, we count tripletons $(k, p, a)$ such that

1) $k$ is an integer greater than 1 ,

2) $a$ is an integer $\geq 1$, and if $p=2$ or $p=3$ and $k=2$ then $a>1$, and

3) $p$ is a prime, and writing $q=p^{a}$ we have

$$
\begin{aligned}
f(k, p, a)=q^{k(k-1) / 2} & \pi \quad\left(q^{1}-1\right) /(k, p-1)=\left|\operatorname{PSL}_{k}(q)\right|<n . \\
1 & =2
\end{aligned}
$$

Artin (5) showed that in exactly two cases distinct tripletons give rise to isomorphic groups, and in one case there are non-1somorphic groups of the same order in that family. Since $f(k, p, a)<q^{k(k-1) / 2} q^{(k(k+1) / 2)-1}<q^{k^{2}}$, $S(n) \gg \mid\{m<n$ : there exists $(k, p, a)$ satisfying 1$), 2)$, and 3$)$ such that $\left.\mathrm{m}=\mathrm{p}^{\mathrm{ak}^{2}}\right\} \mid$. Such tripletons may be counted by a triple sum, and we have $\mathrm{S}(\mathrm{n})>\sum_{\mathrm{a}=1}^{\infty} \quad \sum_{=}^{\infty} \sum_{\mathrm{p}} \sum_{\mathrm{n}} 1 / \mathrm{ak}^{2} \quad$ 1. Constraining a and $\mathrm{k}$ so that $\mathrm{n}^{1 / \mathrm{ak}}{ }^{2} \geq 2$, 


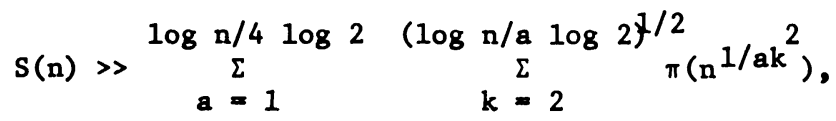

and the Prime Number Theorem using $a=1$ and $k=2$ yields $S(n) \gg n^{1 / 4} / 10 g n$.

This theorem is of interest because it has been conjectured (3) that $S^{\prime}(n)=$ $o\left(n^{1-\varepsilon}\right)$, or even $S^{\prime}(n)=o\left(n^{1 / 3}\right)$. We have that $1 / 4-\varepsilon$ is a lower bound on the exponent of $n$, and if when all simple groups are classified no new family denser than the projective special linear groups appears, analyzing a perhaps more complicated triple sum carefully should yield the best exponent $b$ in the estimate $S^{\prime}(n)=o\left(n^{b}\right)$.

ACKNOWLEDGMENT: I wish to thank Professor Raymond Ayoub of the Pennsylvania State UnIversity for his advice and help.

\section{REFERENCES}

1. Dornhoff, L. Simple groups are scarce, Proc. Am. Math. Soc. 19(1968) 692-696.

2. Dornhoff, L. and E. L. Spitznagel, Jr. Density of finite simple group orders, Math Zeitschrift 106(1968) 175-177.

3. Erdరs, P. Remarks on some problems in number theory, Math. Balcanica 4.32 (1974) 197-202.

4. Hurley, J. and A. Rudvalis. Finite simple groups, Am. Math. Monthly 84 (1977) 693-714.

5. Artin, E. The orders of the linear groups, Comm. Pure and App1. Math. 8(1952) 355-365. 


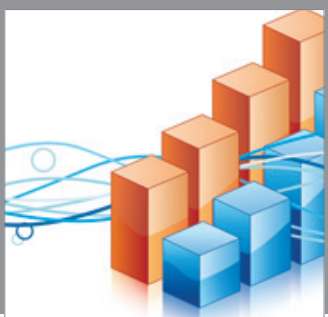

Advances in

Operations Research

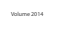

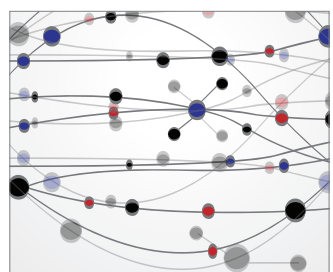

\section{The Scientific} World Journal
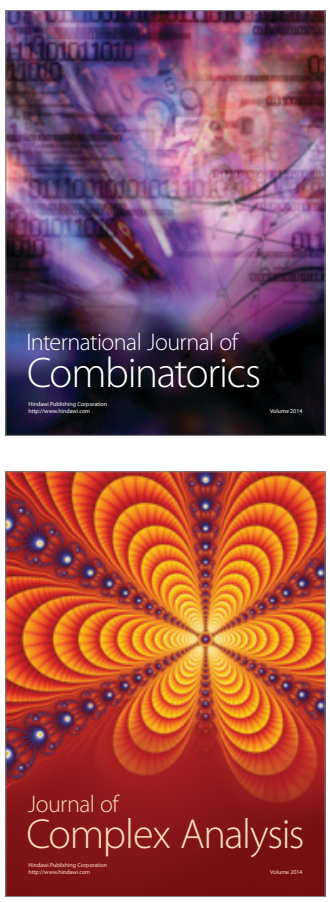

International Journal of

Mathematics and

Mathematical

Sciences
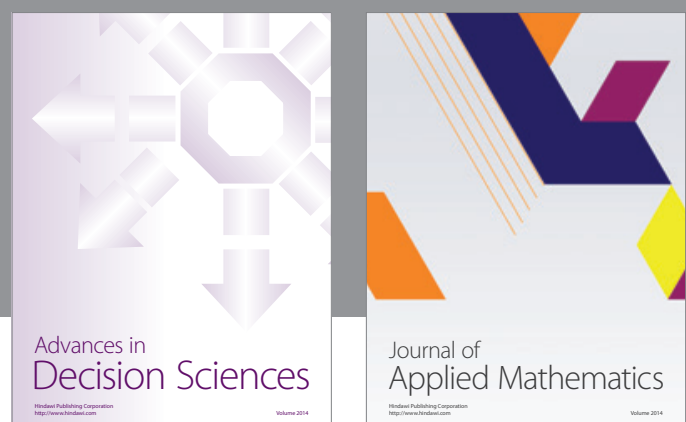

Journal of

Applied Mathematics
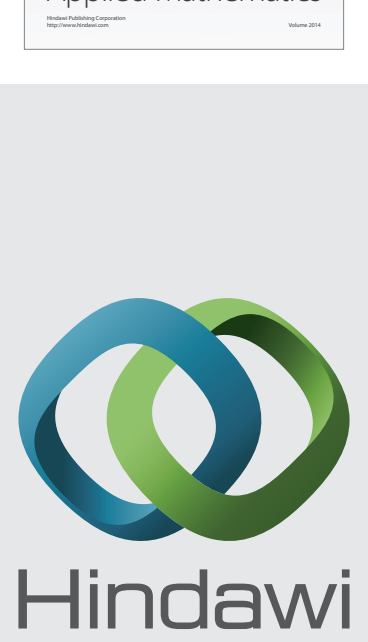

Submit your manuscripts at http://www.hindawi.com
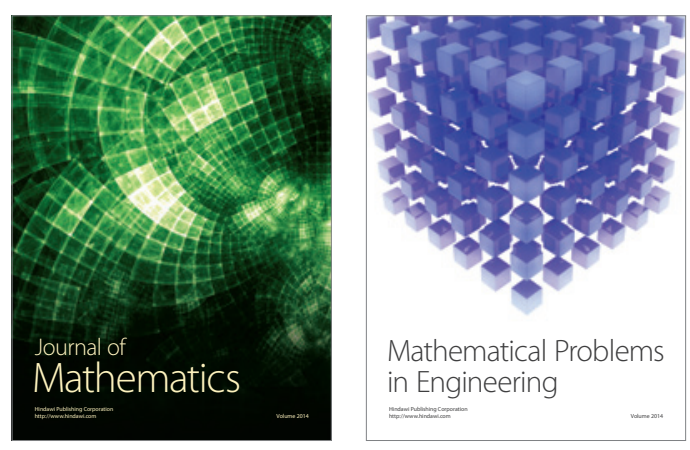

Mathematical Problems in Engineering
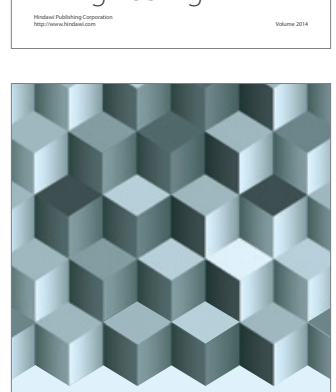

Journal of

Function Spaces
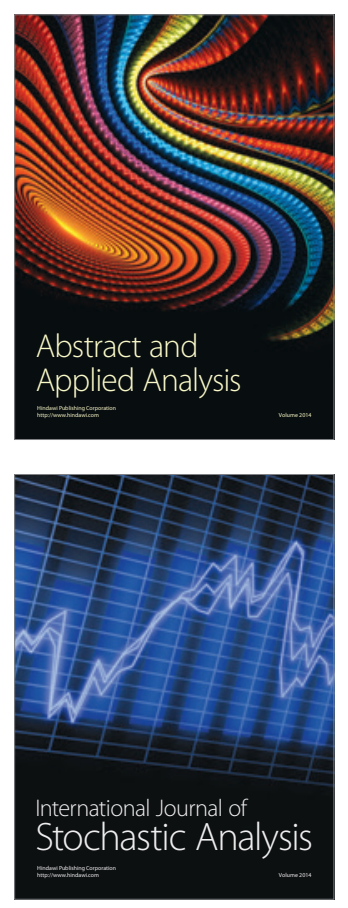

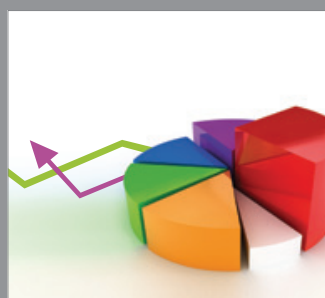

ournal of

Probability and Statistics

Promensencen
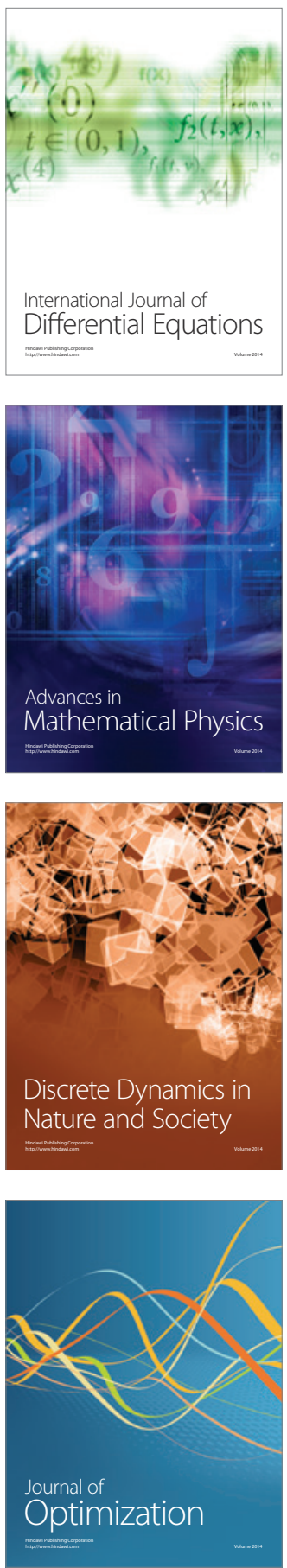